Cuadernos de Historia Moderna

ISSN: 0214-4018

http://dx.doi.org/10.5209/CHMO.56664

\title{
Arte y ciencia en el orbis terrarum. Los europeos y el mundo natural, entre el Barroco y la Ilustración
}

[en] Art and Science in the Orbis Terrarum. Europeans and the Natural World, from the Baroque to the Enlightenment

Juan Pimentel, The Rhinoceros and the Megatherium. An Essay in Natural History, Cambridge (MA) y Londres, Harvard University Press, 2017. Trad. Peter Mason.

José Ramón Marcaida López, Arte y ciencia en el Barroco español, Sevilla y Madrid, Fundación Focus-Abengoa y Marcial Pons, 2014.

Neil Safier, La medición del Nuevo Mundo. La ciencia de la Ilustración y América del Sur, Madrid, Fundación Jorge Juan y Marcial Pons, 2016.

El esplendor final de este arte se mezcla, en las primeras décadas del siglo XVII, con el amanecer del espíritu cientifico, que concibe intelectualmente la realidad partiendo de sus propios hechos.

Wilhelm Dilthey ${ }^{1}$

Una vista panorámica de la situación actual de la historiografía resultaría, en el caso de ser posible, en una imagen de gran heterogeneidad de problemas y métodos. También, por cierto, podríamos llevarnos una impresión de cierta crisis, enunciada de manera explícita por grandes especialistas. ${ }^{2}$ El resultado de ambos fenómenos es que resulta imposible para un historiador cualquiera tener una visión de conjunto de la disciplina o formular juicios globales sobre lo que nuestros trabajos tienen en común. Si yo escribiera, por ejemplo, que hoy los historiadores académicos tendemos a estar de acuerdo en que existen diferencias entre pasado y presente tan cruciales que hacen difícil sostener que a partir del conocimiento histórico podamos prever nuestro porvenir, un colega podría replicar, con toda razón, que existe una revista académica de reciente creación titulada Magistra vitae. En cualquier caso, para los

\footnotetext{
1 "Der letzte Glanz dieser Kunst mischt sich in den ersten Dezennien des 17. Jahrhunderts mit dem Sonnenaufgang des wissenschaftichen Geistes, welcher die Wirklichkeit aus ihren eigenen Tatsachen denkend erfaßt”. DILTHEY, W.: "Der Entwicklungsgeschichtliche Patheismus nach seinem geschichtlichen Zusammenhang mit den älteren pantheistischen Systemen", en Gesammelte Schriften, Leipzig y Berlín, BG Teubner, 1921, p. 324 . El pasaje está editado en español en Hombre y mundo en los siglos XVI y XVII, México, FCE, 1944, pero he corregido levemente la traducción.

2 GruZInSKI, S.: L'Histoire, pour quoi faire?, París, Fayard, 2015.
} 
propósitos de este texto, tal vez sea suficiente con decir que, incluso si descartamos la idea de que conocer lo ocurrido nos permitirá forjar el futuro, uno de los anacronismos irreductibles del oficio es que las preguntas que nos hacemos respecto de tiempos pretéritos provienen de preocupaciones presentes.

Si se acepta como válido, de manera provisoria, este esquema rudimentario, ¿existen inquietudes actuales que contribuyan a explicar el interés por la historia del conocimiento de la naturaleza y su relación con las artes visuales, con las prácticas y personas que intervinieron en su construcción y con el coleccionismo, en ámbitos geográfica y temporalmente extendidos? Aun a riesgo de minimizar en exceso causas, motivaciones y vínculos académicos y editoriales más estrechos, me inclino por una respuesta afirmativa. Parece obvio que vivimos en una época en la que los saberes sobre la naturaleza han llegado a niveles inéditos de precisión y profundidad $\mathrm{y}$, sin embargo, no han cesado ni la curiosidad ni los descubrimientos al respecto, en este y en otros mundos. Esa empresa se ha expandido en volumen y se ha vuelto cada vez más colaborativa, también cada vez más competitiva, lo que en muchos casos ha creado nuevos problemas y actualizado otros ya existentes. ¿Se descubren, en efecto, cosas nuevas? ¿A quién se atribuyen esos descubrimientos? ¿Quiénes se benefician de ellos? ¿Cómo se vinculan esos problemas con la complejidad de personas, instrumentos y prácticas comprometidas en el proceso de producirlos? ¿Se construyen los hechos científicos? ¿Cuál es su relación con la verdad? ¿Cómo representarlos, en textos, matemáticamente, en imágenes, para que otros especialistas puedan contrastarlos y para que quienes no lo son puedan comprenderlos? ¿Seguimos maravillándonos con el mundo natural? Ante la evidencia de que podríamos estar destruyéndolo, ¿cambian nuestra percepción y nuestro interés respecto de cómo nuestros antepasados se relacionaron con él y buscaron entenderlo? Sugiero, en suma, que puede establecerse una relación entre la posibilidad de que los seres humanos causen la extinción de los rinocerontes ${ }^{3}$, de modo que sólo podamos recordarlos, con tristeza y culpa, a partir de imágenes o palabras, y la aparición de un bello libro como The Rhinoceros and the Megatherium.

Por cierto, y antes de entrar en materia, no quisiera insinuar que estos temas y enfoques son una preocupación estrictamente contemporánea, no sólo porque eso no es cierto, sino también porque los autores de los libros que se describen a continuación exponen, entre otras cosas, un sólido conocimiento de los campos en los que se aventuran. Así, por ejemplo, hace tiempo que la inquietud por estudiar fenómenos de historia cultural desde una perspectiva global o conectada ha dejado de ser una novedad para convertirse casi en una práctica aceptada como necesaria, con profundas reflexiones teóricas y debates que abarcan incluso la posibilidad de aproximarse a esa escala desde la microhistoria ${ }^{4}$. También los estudios sociales de la ciencia y la tecnología, particularmente la historia social de la ciencia, tienen una

Mientras escribo estas líneas, recibo la noticia de que cazadores furtivos aniquilaron a un rinoceronte en el zoológico de Thoiry, en Francia. Véase Bardou, F.: "Rhinocéros tué à Thoiry: un acte inédit en Europe et relevant du pénal" [en línea], Libération, 8 de marzo de 2017: www.liberation.fr/futurs/2017/03/08/rhinocerostue-a-thoiry-un-acte-inedit-en-europe-et-relevant-du-penal_1553990 [Última consulta: 18 de marzo de 2017].

4 Sin pretensiones de exhaustividad, señalo apenas como ejemplos las obras de GruZINSKI, S.: Las cuatro partes del mundo, México, FCE, 2010; Subrahmanyam, S.: Explorations in Connected History, Nueva Delhi, Oxford University Press, 2010, Boucheron, P. (dir.): Histoire du monde au XVe siècle, París, Fayard, 2009, Ginzburg, C.: "Microhistory and World History", en Bentley, J. H. y otros (eds.): The Cambridge World History, Cambridge, Cambridge University Press, 2015, pp. 425-445, y por qué no Grafton, A.: New Worlds, Ancient Texts, Cambridge MA y Londres, Harvard University Press, 1995. 
larguísima tradición, en la que estas obras se insertan con honores, y abarcan una amplia gama de aproximaciones, que incluye tanto a quienes imaginan al conocimiento como constructor de lo real cuanto a quienes insisten en que los fenómenos naturales existen pero indagan en los modos (a veces poco inocentes) de construcción, comunicación y validación del saber sobre ellos ${ }^{5}$. En tercer lugar, son abundantes desde hace décadas las pesquisas respecto de los vínculos entre arte y ciencia, en especial entre imagen y ciencia, tanto en el sentido de la producción de conocimiento sobre el mundo natural cuanto en lo referente a la comunicación de esos saberes durante la modernidad temprana ${ }^{6}$. Más específicamente, aunque quizás también más difícil de definir, las tres obras en las que nos detendremos enseguida pertenecen a una frondosa línea de análisis que busca una mejor comprensión de las articulaciones entre la primera globalización, el descubrimiento de lo maravilloso, la cultura visual, el coleccionismo y los albores del conocimiento científico moderno ${ }^{7}$.

El libro de Juan Pimentel, publicado originalmente en español en 2010 y traducido este año al inglés por Peter Mason, comparte con las otras dos obras que analizaremos muchas características, entre las que se cuentan el eje en la historia natural y un horizonte geográfico-temporal comparable. Sin embargo, se distingue de ellas por el género: se trata de un ensayo histórico comparativo y no de un texto estrictamente académico, lo que le permite, desde el inicio mismo, plantearse el entretenimiento del lector como un objetivo. A partir de dos animales, el rinoceronte y el megaterio, conocidos en Europa al comienzo y al final de la revolución científica mediante imágenes compuestas por personas que no vieron a las bestias en vivo y en directo, el autor propone reevaluar el papel de la imaginación en la producción de conocimiento. Las implicancias de este proyecto son múltiples. Por un lado, significa pensar una vez más la forma en que se escribe historia de la ciencia, tanto en el plano de su discurrir pasado, mediante una reconsideración del papel de la rivalidad entre texto e imagen en las formas de acceder al conocimiento del mundo natural, cuanto en lo referente a los métodos del experto en relación con la utilidad de la analogía y la comparación en la construcción del saber sobre el pasado. Por otra parte, la empresa permite constatar la centralidad del mundo ibérico en la circulación de animales,

\footnotetext{
Nuevamente, sólo a título de ilustración, véanse Shapin, S.: A social history of truth, Chicago, University of Chicago Press, 1994; Latour, B. y Woolgar, S.: Laboratory life: the construction of scientific facts, Princeton, Princeton University Press, 1986; SCHAFFer, S.: Trabajos de cristal. Ensayos de historia de la ciencia, 16501900, Madrid: Marcial Pons, 2011.

6 Bibliotecas enteras podrían llenarse con libros al respecto. Entre otros, GomBrich, E.: Arte e ilusión, Barcelona, Gustavo Gili, 1979; BurucúA, J. E.: El libro de la naturaleza. Estudio acerca de las ideas de Galileo Galilei sobre las artes figurativas, Buenos Aires, FFyL, 1984; KrIEGER, P. (ed.): Arte y ciencia, México, Universidad Autónoma de México, 2002; AA.VV.: Léonard de Vinci et l'expérience scientifique au XVIe. Siécle, París, CNRS, 1953; Panofsky, E.: "Artist, Scientist, Genius", en Renaissance News, V, nº 1, 1952; Salerno, L.: "Arte, scienza e collezioni nel Manierismo", en Scritti di storia dell'arte in onore di Mario Salmi, Roma, De Luca, 1961-3, Vol. III, pp. 193-214; BRANCA, V.: Rappresentazione artística e rappresentazione scientifica nel Secolo dei Lumi, Florencia, Sansoni, 1972; BredeKamp, H.: "Gazing Hands and Blind Spots: Galileo as Draftsman”, en Science in Context, 13, 3-4, Cambridge (UK), Cambridge University Press, 2000; Kemp, M.: The Science of Art, New Haven, Yale University Press, 1990.

7 Véanse Daston, L. y PARK, K.: Wonders and the Order of Nature, 1150-1750, Nueva York, Zone Books, 1998; Mason, P.: Infelicities: Representations of the Exotic, Baltimore, Johns Hopkins University Press, 1998; Bleichmar, D., De Vos, P., Huffine, K. y Sheehan, K. (eds.): Science in the Spanish and Portuguese Empires 1500-1800, Stanford, Stanford University Press, 2009; FIndLEN, P.: Possessing nature. Museums, collecting, and scientific culture in Early Modern Italy, Berkeley, University of California Press, 1994; OGILVIE, B. W.: The Science of Describing, Chicago, University of Chicago Press, 2006. Muy probablemente, el último libro de Florike Egmond, Eye for detail, publicado este mismo año por Reaktion Books, habría merecido incluirse en esta reseña conjunta, lo han impedido razones de tiempo y espacio.
} 
objetos, saberes y representaciones. El rinoceronte estudiado llega desde la India a Portugal a inicios del siglo XVI, mientras que los restos del megaterio provienen del Río de la Plata y arriban a Madrid a fines del siglo XVIII; la articulación de esos hallazgos con la producción de imágenes y conocimientos sobre el mundo natural en toda Europa, de la Alemania de Durero a la Francia de Cuvier, no hace más que recordarnos que los vínculos entre Europa y mundos distantes no se quedaban en los puertos, eran necesariamente transnacionales y estaban atravesados por una serie de mediaciones que traslucen, en cada caso, complejas relaciones de poder.

¿Cuáles son, entonces, las historias que nos cuenta Pimentel? La primera parte del libro está dedicada al "paquidermo acorazado" y nos presenta un panorama desbordante de contactos con mundos alejados, relaciones comerciales y políticas, espectáculos cortesanos, crueldad e interacciones entre la importancia simbólica de ciertos animales y el conocimiento de su naturaleza. En 1515 llegó a Lisboa un rinoceronte capturado en la India, acompañado por Oçem, su cornaca, y por el embajador de Alfonso Albuquerque, Jaime Teixeira, quien había obtenido al animal de Muzafar II, sultán de Cambay. La bestia fue bautizada Ganda, la palabra india que da nombre al rinoceronte, y pronto ocupó un lugar destacado tanto en el coleccionismo y la exhibición de animales raros cuanto en la construcción de una imagen estereotipada del exotismo oriental. Una parte de este panorama puede sintetizarse a partir de las decisiones del rey Manuel I y sus consecuencias. El monarca organizó un combate público entre Ganda y un elefante joven, lo que vinculaba a Manuel con las justas de la antigua Roma y recreaba la tensión simbólica entre ambos paquidermos: el rey quería "ver por experiencia" si el animal se comportaba como habían escrito los antiguos. A partir del relato contemporáneo de Damião de Gois, Pimentel nos recuerda que el enfrentamiento reactualizaba un duelo eterno entre el bien y el mal y humanizaba las bestias a partir de descripciones opuestas de sus temperamentos; concluye, igualmente, que la figura de Ganda se volvió el eje de la proyección de una serie de expectativas asociadas con leyendas sobre el unicornio, la sexualidad, el salvajismo y el mundo oriental. Luego del triunfo de Ganda en el duelo, Manuel dispuso que el rinoceronte fuese enviado como presente al papa León X, quien había ya recibido de su parte a Hanno, un elefante por el que sentía gran afecto. Durante el traslado, un naufragio frente a las costas de Marsella acabó con la vida del animal. Sin embargo, el cuerpo de Ganda fue rescatado, embalsamado y enviado a Roma. Más aún, su fama terminó de extenderse por todo el continente gracias a un grabado de Durero, lo que constituye el siguiente eje de análisis en la primera parte del libro. Por un lado, esa imagen hace posible el abordaje de la fertilización recíproca entre arte y ciencia, en este caso a partir del vínculo creciente entre visualización y conocimiento de un hecho y la centralidad de la imitación de la naturaleza en la concepción que Durero tenía de la pintura. Pero el artista nunca vio directamente al rinoceronte que inmortalizó, sino que tuvo acceso a una carta de Valentim Fernandes y a un boceto que la acompañaba gracias al humanista Conrad Peutinger, de modo que reaparece aquí el papel de la imaginación en la construcción del conocimiento, en este caso visual, del animal. El resultado es una representación quimérica, construida a partir del interés de Durero por lo exótico, que integra las características reales del rinoceronte y aquellas imaginarias, provenientes de una larga tradición simbólica. Más aún, como el grabado estaba acompañado de una didascalia, texto e imagen interactúan directamente en la construcción de conocimiento sobre el animal, cuyo impacto cultural se amplifica gracias a la invención técnica del grabado (45 mil co- 
pias se vendieron durante la vida del artista) y la reproducción de la imagen en libros como la Cosmographiae de Sebastian Münster (1544) o la Historia animalium de Conrad Gessner (1551-8).

Si Ganda trasladó el Oriente maravilloso e imaginario a Lisboa, el protagonista de la segunda parte de la obra implicó la vuelta a la vida de una era remota, prodigiosa, geológica, y contribuyó a la emergencia de la idea de la mutabilidad de las especies. El otro polo de la comparación de Pimentel proviene también de una esquina remota del mundo, de las costas del río Luján en este caso, y está igualmente marcado por la ausencia y la imaginación, tal vez más radical en este caso, porque nadie en Europa vio nunca un megaterio vivo. Sin embargo, a fines del siglo XVIII, Juan Bautista Bru de Ramón en el Gabinete Real de Historia Natural de Madrid y Georges Cuvier en el Museo de Historia Natural de París se lanzaron a la tarea de elaborar su imagen a partir de la osamenta recuperada en un extremo de la América austral. Pimentel nos guía por la historia del hallazgo de los fósiles, su traslado transatlántico, las dificultades (y falencias) de su reconstrucción en Madrid y los sentidos simbólicos de una bestia prehistórica eminentemente híbrida. De inmediato, un animal de tamaño descomunal, con dientes de herbívoro y garras de carnívoro, despertó la curiosidad de los científicos, que no dejaron de emplear un lenguaje usado para describir maravillas y prodigios en su intento por dar sentido al descubrimiento. Cuvier, sin embargo, a tono con los tiempos, separó radicalmente la osamenta que nunca vio en directo del contexto en que fue hallada, se desinteresó de sus posibles connotaciones teratológicas y propuso una anatomía correctiva del megaterio a partir de una morfología comparada con animales más pequeños aún vivos (el perezoso, el armadillo y el oso hormiguero). Pero eso no significó, ni mucho menos, el fin de las disputas simbólicas en torno a la historia natural, pues un animal de las dimensiones del megaterio fue pronto empleado retóricamente por los americanos que, como Thomas Jefferson, reaccionaban contra las teorías del conde de Buffon sobre la inferioridad de la naturaleza americana.

The Rhinoceros and the Megatherium ... es un libro cautivante. Las libertades del ensayo permiten al autor incluir a cada paso desviaciones provechosas que entrelazan las historias narradas con otros episodios de la historia de la filosofía natural. Así, dos casos puntuales dan pie a un pantallazo enciclopédico del conocimiento de la naturaleza en la modernidad temprana. El género también induce a algunos riesgos, como la tentación de generalizar respecto de lo que las culturas humanas han hecho siempre o las presuntas características sostenidas del vínculo establecido por los occidentales con Oriente. Pero, en conjunto, Pimentel nos entrega una imagen actualizada de la historia de la ciencia a escala global, atenta a sus detalles singulares, a las zonas de contacto y mestizaje cruciales para su desarrollo y al modo en que "el edificio de la ciencia descansa en la confianza en simulaciones y representaciones de cosas que no hemos visto por nosotros mismos".

Por su parte, el libro de José Ramón Marcaida López está poblado de temas vecinos, aunque no superpuestos. Arte y ciencia en el Barroco español indaga el modo en que el conocimiento de la naturaleza se vincula con objetos usualmente abordados por la historia del arte. Así, encontramos asuntos de la filosofía natural fuera del gabinete y el experimento, en el ámbito de los bodegones, la emblemática y las historias morales. Este abordaje cuestiona la tradición de considerar que la ciencia moderna y el barroco habían sido dos tradiciones inconmensurables, que oponían razón y progreso por un lado y contrarreforma y subjetividad por el otro. De 
acuerdo con el autor, esto permite comprender a la ciencia del período de un modo más abierto a sus relaciones con otras manifestaciones culturales, y ese será el eje de toda la obra, pero también nos acerca a una idea más compleja de las artes visuales de la época. No sorprende, entonces, que Juan Eusebio Nieremberg sea uno de los grandes protagonistas del trabajo, por cuanto su producción intelectual provee ejemplos tanto de la intensidad e importancia de la historia natural cuanto del desarrollo cultural y la centralidad de las preocupaciones por asuntos religiosos en la España del siglo XVII.

El libro se organiza en tres partes. La primera de ellas, "Acumulación", trata del coleccionismo y la cultura material en relación con el conocimiento de la realidad natural. Marcaida López nos propone aquí un abordaje de la vida social y cultural de las cosas, y de sus representaciones en la pintura de gabinete. En este sentido, si las Wunderkammern habían sido el ejemplo palpable de la curiosidad aplicada a la acumulación de objetos, que convertía a la naturaleza en un bien de consumo que podía poseerse y controlarse, las representaciones de esos espacios implican una creciente desmaterialización de las colecciones. Aunque nunca se abandonó el afán por reunir objetos únicos y sorprendentes, ejemplos como el Cuarto Bajo de Verano en el Real Alcázar de Madrid, diseñado durante el reinado de Felipe IV, muestran que éstos estuvieron cada vez más acompañados por imágenes (y libros, por supuesto) que representaban colecciones de cosas raras. El objetivo era siempre observar, describir y catalogar la naturaleza, para dar cuenta del asombro ante la novedad y al mismo tiempo ponerla bajo control. De acuerdo con el autor, si Athanasius Kircher había sido el gran jesuita coleccionista de objetos en el Collegio romano (y el último hombre que lo supo todo), Nieremberg fue uno de los grandes coleccionistas de palabras, con la gran aspiración de explicar la naturaleza "en su integridad" tras el descubrimiento del Nuevo Mundo, lo que a su turno permitiría exaltar la labor creadora de Dios por medio del estudio de los aspectos más extraordinarios de su obra. Nieremberg compuso, así, una Historia naturae (1635), verdadera colección de colecciones, para la cual contó con los materiales de la expedición de Francisco Hernández (1570-77), entonces inéditos y luego destruidos por el incendio de El Escorial de 1671 (los publicaría la Accademia dei Lincei en 1651, como Tesoro Mexicano).

El segundo capítulo, "Representación”, se ocupa de los retratos de cosas de Indias. Marcaida López nos cuenta que, gracias a la historia de El Escorial de José de Sigüenza, sabemos que se exhibían en la Sala del Mediodía cuadros sobre esos temas, que provienen, justamente, del viaje hernandino. El explorador se ocupó, con la asistencia de varios artistas, de documentar en detalle el mundo natural que estudió. Aprendemos que, a la usanza de la época, Hernández insistía en que las imágenes habían sido elaboradas ad vivum, en presencia del objeto retratado, como garantía de fidelidad y exactitud. Pero, igualmente, anunciaba que las había hecho "pintar a mi modo y poner en estilo", algo que evidencia que se trata de síntesis analíticas de varias observaciones, y también de noticias indirectas (incluso hechas a partir de otras imágenes). Se trata de un testimonio fundamental de la capacidad de las imágenes para transmitir conocimiento y de su función como mediadoras de espacios geográficos distantes y entre formas de conocimiento y realidades naturales hasta entonces desconocidas. Pero el asunto no termina allí. Hay, por un lado, una aproximación distinta a las imágenes en diversas historias naturales del período, lo que no depende únicamente de las intenciones de sus autores, sino también de factores editoriales más azarosos. Por otra parte, las representaciones visuales de especímenes botánicos 
no responden solamente a intereses naturalistas. Así, en la Historia de Nieremberg, la precisión realista en el retrato de la flor de la pasión se combina con la búsqueda de un simbolismo bíblico, de acuerdo con el cual el fruto contendría elementos de la Pasión, entre ellos el cáliz, los clavos y la corona de espinas. Más aún, esto fue objeto de debate: Nicolás Monardes ya lo había sugerido en 1574, pero el naturalista inglés John Parkinson criticó la hipótesis como una "superstición de jesuitas" en 1629. Se trata de imágenes que forman parte de la cultura visual científica moderna, pero también del repertorio de temas religiosos, y por ello desmienten una historia de la ilustración científica entendida únicamente en términos de progreso.

El último tercio de la obra se ocupa de la "Preservación" y se pregunta si la preocupación del Barroco por la fugacidad, evidente en el género de la vanitas, puede tener algún vínculo con un efecto concreto de la expansión colonial, comercial y coleccionista: la necesidad de preservar instrumentos, obras de arte y ejemplares. Así, no sería imposible que la elaboración minuciosa y el retrato preciso de la naturaleza en los libros de historia natural inspiraran el mismo fenómeno en los bodegones, donde se articulan también con lecturas religiosas sobre la actividad creadora de Dios en el esplendor de la naturaleza y reflexiones sobre la caducidad de la existencia a partir de la vida simulada y suspendida. Al mismo tiempo, las técnicas de preservación de animales llevados a Europa desde el mundo entero condicionaban tanto la producción de conocimiento natural cuanto las preocupaciones de orden moral y religioso que se derivaban de ellos, tal como lo ilustra el caso del ave del paraíso y los debates en torno a su presunta naturaleza ápoda. Arte y ciencia ... nos propone, en suma, la hipótesis de la existencia de unidad en las artes visuales del Barroco. Eso no significa que arte, ciencia y religión fuesen entonces una misma cosa, pero sí que existían vías de comunicación entre esos campos, que pasaban también por redes de larga distancia establecidas tanto para la acumulación de informaciones y ejemplares de naturalezas lejanas cuanto para la elaboración de imágenes y la impresión de libros que pudiesen ponerlos en circulación. Todo esto demanda considerar una vez más la cultura material barroca, marcada por el coleccionismo pero también por la desmaterialización, por las mediaciones que las imágenes imponen respecto de los objetos y por el desarrollo de formas de expresión visual que permitieran dar cuenta de las relaciones problemáticas entre el plano de lo real y el de las representaciones. Perspectiva, ilusión y trampantojo aparecen así bajo una luz distinta.

La medición del Nuevo Mundo, de Neil Safier, es la traducción española de un libro publicado en Chicago en 2008. Seguimos, por supuesto, en el universo de las relaciones entre ciencia e imágenes en una escala global, aunque en este caso el eje temporal está puesto en la época ilustrada y el conocimiento de la naturaleza se centra en los estudios geodésicos, pero se abre también a lo que Antonello Gerbi llamó "la disputa del Nuevo Mundo" respecto de la presunta inferioridad de la naturaleza y los habitantes de América ${ }^{8}$. Ambos temas ponen en el centro de la cuestión las complejidades de la relación entre expansión imperial y ciencia instrumental. Por un lado, porque en la producción de esos saberes intervinieron europeos de varios orígenes, criollos y nativos, de maneras que todavía no conocemos de forma exacta, y que el libro indaga, pero siempre con un predominio del reconocimiento para algunos de ellos, a partir de un sistema editorial y académico bien establecido. Por el otro, porque las prácticas empíricas debieron adaptarse a condiciones locales en el

Gerbi, A.: La disputa del Nuevo Mundo, México, FCE, 1960. 
Nuevo Mundo, y eso implicaba tomar decisiones (en el gabinete antes de partir, en el terreno una vez llegados, en el camino a la imprenta al regreso) que no dependían enteramente de las intenciones individuales de los naturalistas.

El primer eje analizado en La medición del Nuevo Mundo se refiere a la misión que, entre 1735 y 1744, se estableció en Ecuador con el objetivo de determinar la forma exacta de la Tierra. De ella participaron doce científicos europeos, entre los que se contaban Charles Marie de La Condamine, Antonio de Ulloa y Jorge Juan. Safier describe con gran detalle y sagacidad las condiciones políticas que hicieron posible esa empresa colaborativa (Felipe V, un monarca Borbón, consideraba que patrocinar expediciones científicas demostraría la naturaleza ilustrada de la monarquía y aumentaría su prestigio), las tensiones resultantes entre españoles y franceses, la participación fundamental de los americanos en el desarrollo material y simbólico de la investigación y, finalmente, los hallazgos científicos, sin dejar de lado el modo de su atribución, divulgación y conmemoración. Una de las cuestiones centrales que el texto trae al centro de la escena es, en efecto, que La Condamine narró los hechos en un texto publicado en 1751, donde se atribuye los logros de la expedición y suprime las contribuciones de otros, algo que contemporáneos suyos como el abate AntoineFrançois Prévost ya habían notado. La obra también desvela el proceso de erección de una serie de pirámides para marcar los puntos de observación geodésica, lo que obedecía a la intención de que otros pudieran repetir la experiencia y a objetivos simbólicos, por lo que la Académie des Inscriptions et Belles Lettres intervino en su diseño. Poco debería sorprendernos, a esta altura, que La Condamine entrara en un conflicto con Juan y Ulloa al respecto.

Pero la aventura de La Condamine no terminó en Quito, sino que el francés tomó la decisión de regresar a Europa tras una exploración del Amazonas. De ese viaje también nos dejó un libro, la Relation abrégée d'un voyage fait dans l'intérieur de l'Amérique Méridionale, publicado en 1745. Safier nos muestra el modo en que el científico suprimió sus fuentes criollas, amerindias y africanas para convertirse en el protagonista de su relato en primera persona, expone también el uso de etnografías manuscritas sin citarlas como fuentes, lo que resulta en la caracterización cruel de los indios como indolentes, poco sagaces, glotones e irracionales, y la reproducción de leyendas como la existencia de sociedades ginocráticas y de El Dorado para satisfacer las expectativas de su público. No sólo estas prácticas contrastan con la "ética de la exactitud y la transformación profunda de las prácticas de medición" en la comunidad científica europea entre 1730 y 1740, sino que, además, convirtieron a La Condamine en uno de los objetivos de las críticas de autores como Juan de Velasco y Francisco Javier Clavijero, quien, de hecho, censuró su conocimiento superficial y su ignorancia, entre otras cosas de las lenguas de los indios. También José Monteiro de Noronha y Francisco Xavier Ribeiro de Sampaio lo criticaron duramente. Sin embargo, como es usual, la recepción de la obra fue sinuosa y múltiple; de hecho, en Francia, terminó de forjar la reputación del autor como un cartógrafo preciso y un escritor talentoso.

Estos temas reaparecen en el resto del libro. El cuarto capítulo estudia detalladamente los avatares de la producción y publicación de la Carta de la provincia de Quito de Pedro Maldonado, lo que permite a Safier elaborar el argumento de la colaboración y la competencia a escala global, al tiempo que desnuda una vez más las ambiciones y pequeñas miserias, disfrazadas de generosidad y abnegación, presentes en algunos naturalistas ilustrados. Sin embargo, el autor no cae en la tentación de 
impugnar in toto el conocimiento geográfico ilustrado, sino que insiste en verificar la importancia del manuscrito para fijar significados en un impreso y la dependencia del conocimiento cartográfico tanto de procesos sociales y materiales en la imprenta como de la exploración en el terreno. En el capítulo siguiente, el estudio de la Relación histórica de Juan y Ulloa, publicada en 1748, permite tanto recuperar las polémicas respecto de las capacidades y habilidades de los indios, en este caso en el interior del imperio español, cuanto reevaluar la ciencia empírica ibérica a la luz de sus disputas intelectuales y territoriales con los franceses, en los campos de la geografía, la etnografía y la historia natural, que se entrelazan en el relato. En el trasfondo de estas discusiones están los problemas de la distancia etnográfica y la distancia geográfica, al igual que el hecho de que los indios, cuyas capacidades y valía aparecen en el centro del debate, son silenciados y discutidos como objetos de estudio, sin potestad de intervenir en la discusión. El análisis de los Comentarios reales de Garcilaso y de los avatares de su edición y traducción, en el sexto capítulo de $L a$ medición del Nuevo Mundo, establecen un balance necesario respecto de este punto.

Lejos de considerar, con Marie Louise Pratt, que las expediciones ilustradas fueron simplemente un instrumento de la dominación colonial, el atento estudio de Safier muestra la existencia de conflictos y desafíos entre naciones, academias, individuos. Estas tensiones, a su turno, desmienten las aspiraciones universales de la ciencia europea y sus prácticas de representación, algo que se comprende cabalmente a partir de la reconstrucción de las prácticas materiales, las relaciones sociales y las etapas de elaboración y producción textual respecto del mundo natural y humano. Para Safier, resulta evidente que no se trataba de un conocimiento universal omnisciente, sino de uno parcial y contingente. Si los naturalistas ilustrados no fueron a América del Sur para leer tímidamente el libro de la naturaleza, sino con la intención de ingresar en el escenario científico metropolitano, sigue en pie la paradoja de que, incluso en ese "vasto teatro", leyeron con bastante precisión algunas páginas de ese libro (que revelan la forma del planeta, por ejemplo) y con lentes, deformantes hasta el grotesco, aquellas referidas a la etnografía americana.

¿Qué nos muestran, en su conjunto, estas tres obras? De una parte, atestiguan no sólo la existencia de prácticas e intereses compartidos en los estudios de historia de la ciencia en español y en el mundo anglosajón: indicio de ello son las traducciones cruzadas de los libros de Safier y Pimentel y el hecho de que Marcaida López trabaje, hoy, en la Universidad de Cambridge. Además, los tres textos exhiben la vitalidad de una aproximación que no es nueva, pero que sigue rindiendo frutos, y que no se deja constreñir por los límites estrechos entre las disciplinas. Examinar las relaciones entre conocimiento natural y artes plásticas no solamente da cuenta de fenómenos puntuales en el desarrollo de la ciencia y la pintura, sino que además nos ofrece panoramas nuevos acerca de la complejidad de las interrelaciones entre esferas culturales durante la modernidad temprana. Igualmente, concebir el problema del surgimiento de la ciencia moderna con un ojo atento a sus dimensiones sociales y materiales, desde una perspectiva ampliada y comparativa que no se detenga ante fronteras nacionales, hace posible trazar nuevos mapas, observar mejor movimientos antiguos y entender de un modo más preciso la complejidad de la producción del conocimiento. Por último, Pimentel, Marcaida López y Safier ponen en cuestión el argumento inicial, aquel sobre la dificultad de una imagen de conjunto de la historiografía actual. Es cierto, la historia de la ciencia durante la modernidad temprana no es, ni de cerca, la totalidad del campo, pero los tres autores demuestran que las 
visiones de conjunto son posibles, al menos en este espacio restringido.

Nicolás Kwiatkowski Universidad Nacional de San Martín - CONICET, Argentina 